A C T A C H E M I C A S C A N D I N A V I C A 12 (1958) $489-494$

\title{
The State of Order in Cellulose as Revealed from X-Ray Diffractograms
}

\author{
JON GJÖNNES, NIGOLAI NORMAN And HENRY VIERVOLL
}

Central Institute for Industrial Research, Oslo, Norway

\begin{abstract}
A comparison has been made between the diffracted X-ray intensity from samples of cellulose and synthetized intensity curves, and it is shown that much more of the X-ray scattering from cellulose can be ascribed to crystalline reflexions than previously done. Thus the recorded intensity from samples of cellulose I (native) to a fair degree of approximation can be explained without introducing the concept of amorphous cellulose. For cellulose II(regenerated) the diffractograms can not be considered built up exclusively of crystalline reflexions, though also here the difference in cellulose qualities more seems to lie in the degree of perfection of the best ordered part of the samples than in different amounts of crystalline and amorphous material.
\end{abstract}

Several investigations have been carried out in order to determine the degree

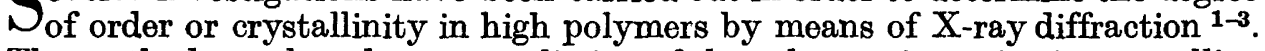
The methods are based upon a splitting of the coherent intensity in crystalline peaks and a continous background which is ascribed to an amorphous fraction of the sample. The coherently diffracted radiation is consequently interpreted as the sum of intensity scattered from crystalline material and from amorphous material .

The essential point in crystallinity measurements by $\mathrm{X}$-ray methods has been the separation of the intensity into these two components. For substances like polyethylene where the crystalline reflexions are clearly superimposed upon a background due to the scattering from the solidified melt ${ }^{2}$, the separation is simple and unambiguous. In the diffraction pattern for cellulose the crystalline reflexions are very broad and partly overlap. Consequently the drawing of a curve separating the two intensities is more difficult. In the procedures used by Hermans ${ }^{1}$ and by Ellefsen, Wang Lund, Tönnesen and Oien ${ }^{3}$ this curve touches the total intensity curve, implying that the coherent scattering from the crystalline fraction is set equal to zero at the corresponding Bragg angles. 


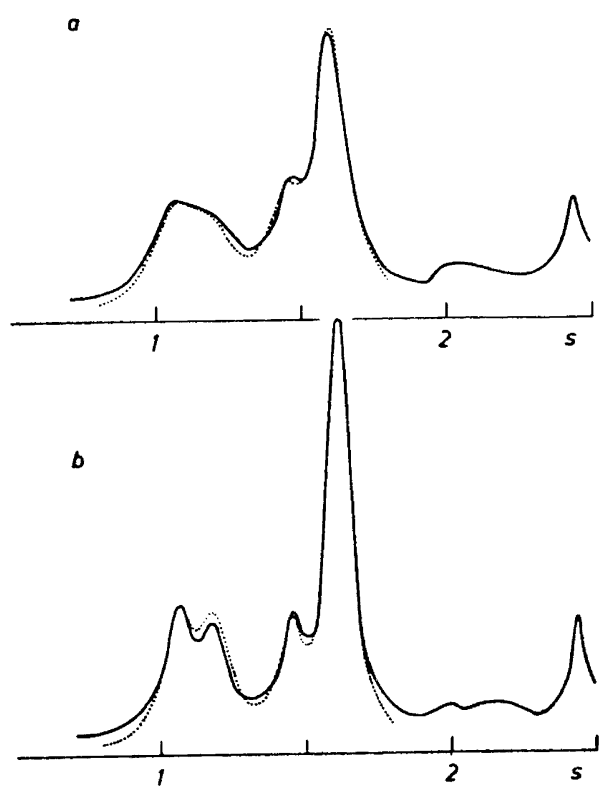

Fig. 1. Experimental (full-line) and synthetized (dotted) intensity curves for cellulose I.

a. Acetate grade wood pulp

b. Sulphuric acid treated surgical cotton

It is well known that small particle size and lattice distortion will cause a broadening of the peaks in the diffractogram, involving a general rise in background due to superposition of the tails of the lines. For cellulose the lines are very broad presumably due to both these factors. It is thus reasonable to believe that the lines may give a considerable contribution to the background in the diffractograms. In order to evaluate how far the description based on crystalline reflexions may fit the experimental data, a comparison has been made between experimental intensity curves and synthetized curves based on a limited number of crystalline reflexions.

\section{THE EXPERIMENTAL AND SYNTHETIZED CURVES}

Powder diffractograms of unoriented samples of cellulose were obtained in a Guinier vacuum camera with $\mathrm{Cu} K \alpha$-radiation. The intensity curves were corrected for absorption and polarization and normalized to the background of incoherent and structure independent coherent scattering from a glucose unit ${ }^{4}$. After normalization the incoherent scattering was subtracted.

In the calculated intensity curves the crystalline peaks were supposed to have the shape of a Cauchy distribution:

$$
I(\mathrm{~s})=K \frac{\alpha}{\alpha^{2}+\left(s-s_{0}\right)^{2}}
$$


Here $s=4 \pi \sin \Theta / \lambda, s_{0}$ is the peak abscissa, and $2 \alpha$ the half width of the peak. $K$ is a constant that depends on the structure factor of the reflexion. A characteristic feature of the Cauchy distribution is the long tails which was one reason why this function was chosen for cellulose. The Cauchy line profile has been observed for the reflexions of cold worked metals ${ }^{5}$, and a study of the diffractograms of cellulose in fact seems to confirm that the well resolved peaks to a fair degree of approximation can be represented by Cauchy distributions.

The position of the lines were determined from the experimental intensity curves, and these curves were further used in the estimation of half widths. Since the structure factors for cellulose are not well known, the values of $K$ also had to be evaluated from the measurements.

In the calculations only the reflexions $\left(\begin{array}{lll}1 & 0 & 1\end{array}\right),\left(\begin{array}{lll}1 & 0 & 1\end{array}\right),\left(\begin{array}{lll}0 & 2 & 1\end{array}\right)$ and $\left(\begin{array}{lll}0 & 0 & 2\end{array}\right)$ for

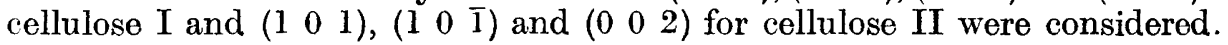

\section{RESULTS}

Four different qualities of cellulose I (native) and cellulose II (regenerated) were investigated. The full-line curves in Fig. 1, $a$ and $b$, show the corrected intensity from an acetate grade wood pulp and a sulphuric acid treated surgical cotton, respectively. The dotted curves represent the calculated intensity based on the values of $s_{\mathrm{o}}, K$ and $2 \alpha$ in Table 1 . In the same way the experimental and calculated intensity curves for the two samples of cellulose II are given by the full-line and dotted curves in Fig. 2. Curve $a$ corresponds to an acetate grade wood pulp mercerized in $18 \%$ sodium hydroxide, curve $b$ to acetate grade wood pulp treated with $39 \%$ hydrochloric acid. The values of the parameters are found in Table 2.

\section{DISCUSSION}

In its broad features the agreement between experimental and calculated intensities in Figs. 1 and 2 up to $s=1.7-1.8$ is satisfactory. Above this value of $s$ it is easy to obtain a good fit because of the large number of reflexions. There also exist crystalline reflexions below $s=1.7$ which are not taken into consideration in the calculations and which would add to the theoretical

Table 1. Parameters used in the calculation of intensity curves for cellulose I.

\begin{tabular}{|c|c|c|c|c|}
\hline \multirow{2}{*}{ Reflexion } & \multirow{2}{*}{$s_{0}$} & \multirow{2}{*}{$K$} & \multicolumn{2}{|c|}{$2 \alpha$} \\
\hline & & & Wood pulp & Cotton \\
\hline 101 & 1.06 & 25 & 0.20 & 0.12 \\
\hline $10 \overline{1}$ & 1.18 & 25 & 0.21 & 0.13 \\
\hline 021 & 1.45 & 18 & 0.13 & 0.09 \\
\hline $\begin{array}{lll}0 & 0 & 2\end{array}$ & 1.61 & 66 & 0.14 & 0.10 \\
\hline
\end{tabular}


Table 2. Parameters used in the calculation of intensity curves for cellulose II.

\begin{tabular}{|c|c|c|c|c|}
\hline \multirow{3}{*}{ Reflexion } & \multirow{3}{*}{$s_{0}$} & \multirow{3}{*}{$K$} & \multicolumn{2}{|c|}{$2 a$} \\
\hline & & & \multicolumn{2}{|c|}{ Acetate grade wood pulp } \\
\hline & & & $18 \% \mathrm{NaOH}$ & $39 \% \mathrm{HCl}$ \\
\hline $\begin{array}{lll}1 & 0 & 1 \\
1 & 0 & 1\end{array}$ & $\begin{array}{l}0.87 \\
1.43 \\
1.56\end{array}$ & $\begin{array}{l}15 \\
61\end{array}$ & $\begin{array}{l}0.12 \\
0.14 \\
0.14\end{array}$ & $\begin{array}{l}0.06 \\
0.09\end{array}$ \\
\hline $\begin{array}{lll}0 & 02\end{array}$ & $1.57 * *$ & 37 & & 0.07 \\
\hline
\end{tabular}

* Fig. 2 a, ** Fig. 2 b

intensity distribution and bring out a better fit between experimental and synthetized curves.

Fig. 1 shows a good correspondance between experimental and calculated intensity curves. This seems to indicate that the greater part of the investigated samples of cellulose I very likely consists of aggregates of distorted crystallites, and that only small quantities of highly disordered material are present.

For cellulose II the case is somewhat different. The background, especially in the region between the $\left(\begin{array}{lll}1 & 0 & 1\end{array}\right)$ and $\left(\begin{array}{lll}1 & 0 & \overline{1}\end{array}\right)$ lines in Fig. 2, can not be explained

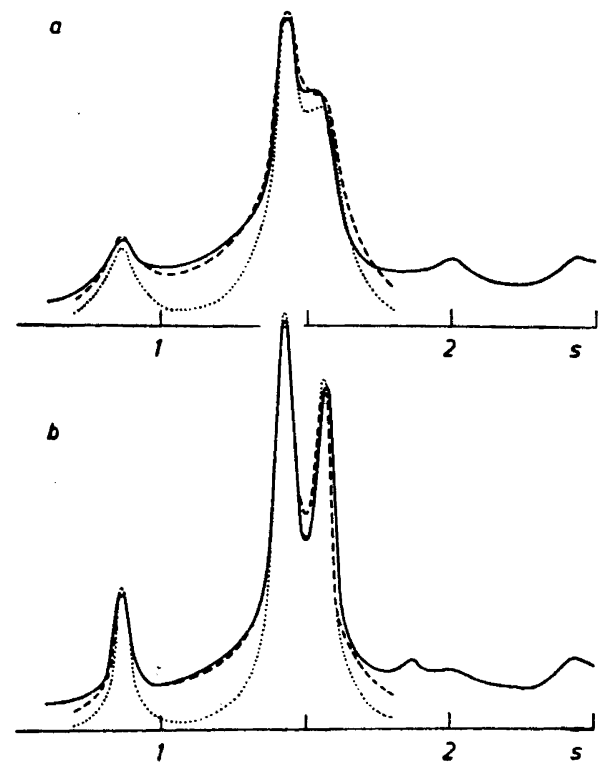

Fig. 2. Experimental'(full-line) and synthetized (dotted) intensity curves for cellulose II. The broken curves, correspond to synthetized intensities including an amorphous background.

a. Acetate grade wood pulp mercerized in $18 \%$ sodium hydroxide

b. Acetate grade wood pulp treated with $39 \%$ hydrochloric acid. 
Table 3. Computed values for the degree of amorphity by the method of Ellefsen, Wang Lund, Tönnesen and OOien ${ }^{3}$.

\begin{tabular}{|c|c|c|}
\hline Modification & Sample & $\begin{array}{c}\text { Degree of amorphity } \\
\%\end{array}$ \\
\hline $\begin{array}{cc}\text { Cellulose } & \text { I } \\
* & \text { I } \\
& \text { II } \\
& \text { II }\end{array}$ & $\begin{array}{l}\text { Acetate grade wood pulp } \\
\mathrm{H}_{2} \mathrm{SO} \text {-treated surgical cotton } \\
\text { Acetate grade wood pulp } \\
\text { merc. in } 18 \% \text { NaOH } \\
\text { Acetate grade wood pulp } \\
\text { treated with } 39 \% \text { HCI }\end{array}$ & $\begin{array}{l}47 \\
38 \\
\\
57 \\
51\end{array}$ \\
\hline
\end{tabular}

exclusively as due to the outer parts of the crystalline reflexions of the assumed shape, even if the unresolved $\left(\begin{array}{lll}0 & 2 & 0\end{array}\right)$ peak at $s_{0}=1.22$ is added. It is also seen that the half widths of the peaks are considerably smaller than those obtained for cellulose I. Both these facts suggest that the cellulose II samples to a higher extent than the samples of cellulose I are separable into fractions with widely different states of order. These may well include an amorphous one, corresponding to the dry ground cellulose defined as amorphous cellulose by Ellefsen et $a .^{6}$

From the broken curves in Fig. $2 a$ and $b$ it is seen that a better correspondance between experimental and calculated intensity curves can be obtained when an amorphous background is added to the theoretical intensity. These curves represent the superposition of scattering curves from dry ground samples of cellulose and the calculated intensities given by the dotted curves of the same figure. The ordinates were reduced to fit the estimated contents of crystalline material. The broken curves in Fig. $2 a$ and $b$ both correspond to $40 \%$ amorphous material. For the same samples the method of Ellefsen et $a l^{3}$ led to the values $57 \%$ and $51 \%$, respectively (Table 3 ). It should be mentioned that the adding of an amorphous background also can improve the agreement between experimental and calculated intensity curves for cellulose $\mathrm{I}$, and that a value around $5 \%$ seems to give the best fit for both samples.

\section{CONCLUSION}

The present paper shows that it is possible to obtain good correspondance between experimental intensity curves and synthetized curves based on the sum of broad crystalline reflexions and an amorphous background. This superposition of intensities does not necessarily correspond to the true state of order in the sample. However, if a separation of the observed intensity into two components is carried out, it should be kept in mind that a considerable part of the background in the diffractogram is due to the crystalline peaks.

It should be pointed out that for samples of the same modification of cellulose, the difference in state of order seems to lie more in the degree of perfection of the best ordered fraction than in the ratio between this fraction and

Acta Chem. Scand. 12 (1958) No. 3 
the less ordered one. This is clearly illustrated in Fig. 2 where the calculations led to the same amount of amorphous material for the two samples, although the diffractograms show marked differences. These differences are expressed in the half widths used for computing the synthetized curves.

It is thus evident that any description of order or crystallinity in cellulose should take the intrinsic order of the crystallites into consideration. 'The half widths of the peaks here seem to be suitable parameters. Further experimental and theoretical work along this line is in progress.

This investigation is part of a research program on the structure of cellulose carried out by the Central Institute for Industrial Research and The Norwegian Pulp and Paper Research Institute. Financial support from the Royal Norwegian Council for Industrial Research is gratefully acknowledged.

\section{REFERENCES}

1. Hermans, P. H. and Weidinger, A. J. Appl. Phys. 19 (1948) 491.

2. Krimm, I. and Tobolsky, A. V. J. Polymer Sci. 7 (1951) 57.

3. Ellefsen, Ö., Wang Lund, E., Tönnsen, B. A. and Öien, K. Norsk Skogindustri 11 (1957) 349. Part II.

4. Norman, N. Acta Cryst. 10 (1957) 370.

5. Williamson, G. K. and Smallman, R. E. Acta Cryst. 7 (1954) 574.

6. Ellefsen, Ö., Wang Lund, E., Tönnesen, B. A. and Öien, K. Norsk Skogindustri 11 (1957) 284. Part I.

Received November 19, 1957. 